\title{
Core clock gene Bmal1 deprivation impairs steroidogenesis in mice luteinized follicle cells
}

\author{
Yizi Wang ${ }^{1,3}$, Minghui Chen ${ }^{1,3}$, Jian Xu(1),2, Xinyan Liu¹,3, Yuwei Duan¹,3, Canquan Zhou ${ }^{1,3}$ and \\ Yanwen Xu(1) ${ }^{1,3}$ \\ ${ }^{1}$ Reproductive Medicine Center, The First Affiliated Hospital of Sun Yat-sen University, Guangdong, Guangzhou, \\ China, ${ }^{2}$ Reproductive Medicine Center, Guangzhou Women and Children's Medical Center, Guangzhou Medical \\ University, Guangzhou, China and ${ }^{3}$ Guangdong Provincial Key Laboratory of Reproductive Medicine, First Affiliated \\ Hospital of Sun Yat-sen University, Guangzhou, China
}

Correspondence should be addressed to Y Xu; Email: xuyanwen663000@126.com

\begin{abstract}
Luteinization is the event of corpus luteum formation, a way of follicle cells transformation and a process of steroidogenesis alteration. As the core clock gene, Bmal1 was involved in the regulation of ovulation process and luteal function afterwards. Till now, the underlying roles of luteinization played by Bmal1 remain unknown. To explore the unique role of Bmal1 in luteal steroidogenesis and its underlying pathway, we investigated the luteal hormone synthesis profile in Bmal1 knockout female mice. We found that luteal hormone synthesis was notably impaired, and phosphorylation of PI3K/NfKB pathway was significantly activated. Then, the results were verified in in vitro cultured cells, including isolated Bmal1 interference granulosa cells (GCs) and theca cells (TCs), respectively. Hormones levels of supernatant culture media and mRNA expressions of steroidogenesis-associated genes (star, Hsd3 32 , cyp19a1 in GCs, Lhcgr, star, Hsd3ß2, cyp17a1 in TCs) were mutually decreased, while the phosphorylation of PI3K/NfKB was promoted during in vitro luteinization. After PI3K specific-inhibitor LY294002 intervention, mRNA expressions of Lhcgr and Hsd3 32 were partially rescued in Bmal1 interference TCs, together with significantly increased androstenedione and T synthesis. Further exploration in TCs demonstrated BMAL1 interacted directly but negatively with NfiB p65 (RelA), a subunit which was supposed as a mediator in Bmal1-governed PI3K signaling regulation. Taken together, we verified the novel role of Bmal1 in luteal steroidogenesis, achieving by negative interplay with RelA-mediated PI3K/NfKB pathway.

Reproduction (2020) 161 955-967
\end{abstract}

\section{Introduction}

Brain and muscle Arnt-like 1 (Bmal1) is the core component of the internal circadian clock system, which has been proved to be indispensable to maintain the mammalian circadian rhythms (Huang et al. 2012, Sellix 2015). Bmal1 deprivation could bring about endogenous or entrainable oscillation alteration (Boden et al. 2010). Up to $10 \%$ of transcriptome in human was expressed in circadian manner (Panda et al. 2002). However, rhythmicity of subordinate clocks was not completely governed by single master pacemaker but showed tissue-specific characteristics (McDearmon et al. 2006, Zhang et al. 2014). Recently, extensive noncircadian regulation patterns of Bmal1 were confirmed in many peripheral biological processes (Alvarez et al. 2003). For example, germline Bmal1 loss results in an acceleration of aging but adult-life inducible knockout ones do not have such gross effects, while both are deficient in the circadian cock (Yang et al. 2016).

In ovary, luteinization is a transient process orchestrated by endocrine, paracrine and autocrine signals in a timely manner after ovulation. Both granulosa and theca cells in the ovulated follicle undergo luteinization to form corpus luteum, which are responsible for the synthesis of progesterone and estrogen required for maintaining early pregnancy before the placenta establishment. Evidences from previous studies have implicated that Bmal1 was involved in the regulation of ovulation process and luteal function afterwards (Boden et al. 2010, Pan et al. 2020, Sen \& Hoffmann 2020). Epidemiologically, shift on sleep-wake schedules might lead to spotting or other abnormalities in luteal phase (Shibui et al. 2000, Wang et al. 2016). Physiologically, verified by immunohistochemistry, BMAL1 expression significantly increased during corpus luteum formation (Wiggins \& Legge 2016). Female mice with Bmal1 knockout were inspected with impaired steroidogenesis, corpus luteum defect, and consequentially increased risks of implantation failure (Ratajczak et al. 2009, Boden et al. 2010, Sellix 2015). Furthermore, serum progesterone concentrations were at a comparative lower levels at the 3.5 day of gestation in Bmal1-/- pregnant mice (Ratajczak et al. 2009), a 
primary pregnancy stage when endogenous hormones were maintained mainly by corpus luteum prior to placenta formation.

The defects in ovulation and luteum function in Bmal1-/- mice were mainly considered to be due to the abolishment of circadian regulation on HPO (hypothalamic-pituitary-ovarian) axis. However, peripheral roles of Bmal1 in ovary could not be ignored. In the mouse model with Bmal1 specifically abolished in ovaries generated in the study of Liu et al., ovarian-targeted Bmal1 deprivation evoked embryonic implantation impairment and simultaneously compromised serum progesterone concentrations (Liu et al. 2014). Subsequently, ovarian cell type-specific Bmal1 knockout mice were generated by Mereness et al. Analogic phenotype as premature primordial follicle aggregation observed in Bmal1-/- mice was merely detected in mice with targeted deletion of the Bmal1 locus in theca cells (TCs) (TCKO), but not in those females with granulosa cells (GCs) Bmal1 knockout (GCKO) (Mereness et al. 2016). When concerning luteinization, speculations were raised whether regulations governed by Bmal1 were achieved mainly through ovarian TCs other than GCs, although the majority studies to date had tended to emphasis GCs' roles rather than TCs'.

Till now, molecular mechanisms of Bmal1 in ovary underlying early luteinization after ovulation still remain elusive and definitely deserve further exploration. By sequence comparison to classic circadian clockcontrolled cir-regulatory elements (E-box, D-box and RORE) (Takahashi 2017), several steroidogenesis associated genes expressed in both GCs and TCs (Star, Lhcgr, Hsd3ß2, and Ptgs2), exclusively in GCs (Fshr, Cyp19a1), or exclusively in TCs (Cyp17a1) were detected in presence with one or more aforementioned elements in their promoters. In consideration of the aforementioned evidences, the implicated hypothesis about whether Bmal1 affected luteal hormone synthesis through entraining steroidogenic-associated genes with clock-controlled promoters directly or via other cellular mechanisms still need to be unraveled.

Given GCs and $\mathrm{TCs}^{\prime}$ critical involvement in steroidogenesis and their cell-specific characteristics during luteinization, it is imperative to further explore the roles of Bmal1 in these two kinds of cells separately. Therefore, the main purpose of the present study was to investigate the assigned roles of Bmal1 in cultured GCs and TCs, respectively, during luteinization, and to explore relevant cellular mechanism using both Bmal1 knockout mouse model and Bmal1-knockdown cultured cells in vitro.

\section{Materials and Methods}

\section{Animals}

Heterozygous Bmal1 knockout mice on C57BL/6] background was purchased from Nanjing Biomedical Research Institute of Nanjing University. Age-matched
WT C57BL/6J mice were purchased from the Guangdong Province Laboratory Animal Center. Female Bmal1-/_ offspring were developed by heterozygous pairs mating, whose genotype were determined as previously described (Bunger et al. 2000). The feeding conditions and Zeitgeber time definition were described in our published paper (Xu et al. 2016), as from 06:00 h (Zeitgeber time 0, ZT 0) light: 18:00 h darkness cycle (ZT 12). All experimental protocols, including animals were approved by the Ethical Committee of the First Affiliated Hospital of Sun Yat-Sen University.

\section{Serum hormone measurements}

The estrous of 8-week-old female mice were synchronized as previously described (Park et al. 2014). One week later, females received an intraperitoneal injection (i.p.) of 15IU pregnant mare serum gonadotrophin (PMSG; Ningbo Second Hormone Factory, Ningbo, China) at 08:00 h (ZT 2) followed by 10IU human chorionic gonadotropin (HCG, sigma) after $48 \mathrm{~h}$. Twenty-four, $36,48 \mathrm{~h}$ (functional stage of luteal phase) and 72, 96 $\mathrm{h}$ (regression stage) later after PMSG/HCG injection (Park et al. 2014), whole blood samples were over time collected by cardiac puncture just after sacrificed by cervical dislocation. Before centrifugation, blood was allowed to coagulate at room temperature for $1 \mathrm{~h}$. Serum was separated according to manufacture protocol and stored at $-80^{\circ} \mathrm{C}$ until assayed. Estradiol and progesterone levels were measured analyzed by RIA using commercial iodine [125I] RIA Kits (Beijing North Biotechnology Research Institute). The sensitivity of the progesterone and estradiol RIA assays was $20 \mathrm{ng} / \mathrm{mL}$. The intra-assay error and inter-assay error were $<10$ and $<15 \%$, respectively.

\section{Isolation and identification of granulosa cells and theca interstitial cells}

Four- to 5-week-old SPF WT female mice at proestrus stage were super-ovulated by an intraperitoneal injection (i.p.) of $15 \mathrm{IU}$ pregnant mare serum gonadotrophin (PMSG; Ningbo Second Hormone Factory, Ningbo, China) at 08:00 $\mathrm{h}$ (ZT 2). Mice were humanely sacrificed by cervical dislocation $48 \mathrm{~h}$ after injection.

By puncturing follicles from the isolated ovaries with a 26 gauge needle immediately, granulosa cells were liberated and collected into precooled DMEM-F12 media. Residual tissue was reserved for TCs collection. GCs suspensions were filtered through $40 \mu \mathrm{m}$ nylon filter and then centrifuged at $250 \mathrm{~g}$ for $5 \mathrm{~min}$. Sediments were collected and centrifugation procedure was repeated twice. Supernatant was discarded and the cells seeded into a 24 -well culture plated $\left(2 \times 10^{5}\right.$ cells/well). Every 2-3 days, half of the cultured DMEM/F-12 (1:1) media (containing $100 \mathrm{U} / \mathrm{mL}$ penicillin, $100 \mathrm{U} / \mathrm{mL}$ streptomycin, $15 \%$ fetal bovine serum and $10 \mathrm{ng} / \mathrm{mL}$ EGF) was replaced with fresh one. TCs isolation was performed according to 
the method previously described (Tian et al. 2015) with slight modification as follows: $4 \mathrm{~mL}$ of $33 \%$ Percoll was layered on top of the $45 \%$ Percoll solution, on top of which the dispersed cells were gently layered, and tubes were centrifuged at $400 \mathrm{~g}$ for $15 \mathrm{~min}$. Then by aspiration inside the $33 \%$ Percoll layer followed by centrifugation at $400 \mathrm{~g}$ for $5 \mathrm{~min}$, the sediments were collected. The final pellet of TCs was resuspended in the reported culture media volume after washing twice with McCoy's 5a medium.

Isolated cells were counted with a hemacytometer and a trypan blue staining was applied to test its viability. FSHR (follicle-stimulating hormone receptor) and CYP17A1 antibody, as specific marker enzyme expressed in GCs and TCs, respectively, was utilized to verify the purity and cell types according to a previous report by immunofluorescence staining (Chen et al. 2013a). Briefly, after 4\% paraformaldehyde fixation and $0.1 \%$ Triton X-100 penetrating cell membrane, cells were incubated overnight at $4^{\circ} \mathrm{C}$ with rabbit anti-mouse FSHR antibody (1:200 dilution, Novus) and rabbit antimouse CYP17A1 (1:200 dilution, Santa Cruz). After washing in PBS, the cells were incubated for $1 \mathrm{~h}$ at $37^{\circ} \mathrm{C}$ with a secondary biotinylated donkey anti-rabbit IgG antibody (dilution 1:300, Santa Cruz). The cells were then washed in PBS and incubated for $10 \mathrm{~min}$ at $37^{\circ} \mathrm{C}$ with DAPI dye liquor. The staining of FSHR was recorded with a laser confocal microscope (Olympus CKX41). A positive staining was evaluated by a green fluorescence for CYP17A1 (1:200 dilution, Santa Cruz), and blue fluorescence represented FSHR (1:200 dilution, Novus).

\section{MTS}

Ovarian cell viability was evaluated based on MTS method by applying MTS assay kit (Abcam, ab197017) according to the manufacturer's instructions. In brief, 48-h post-Bmal1 siRNA transfection (as zero point at horizontal axis), $20 \mu \mathrm{L} /$ well of the MTS was added to cultured TCs and GCs $\left(5 \times 10^{4}\right.$ cells/well in $180 \mu \mathrm{L}$ fresh medium in 96-well plates) for an additional $4 \mathrm{~h}$ of incubation under $37^{\circ} \mathrm{C}$, respectively, at 24-, 48- and 72-h point in time. Untransfected cells were served as the control. Absorbance at $\mathrm{OD}=490 \mathrm{~nm}$ was measured using microplate reader (Daojin UV-2450), and results were expressed as a percentage of the untreated control.

\section{SiRNA transfection}

Three systemic siRNA targeting Bmal1 with fluorescenceFITC labeling for mice were delivered into primary theca cells using Lipofectamine 3000 transfection kit (Invitrogen Corp) 1 day after cell plating when the cell density reached $60 \%$. The planted density was $5 \times 10^{5}$ at each well in six-well plant with $5 \mu \mathrm{L} /$ well FITC siRNALipofectamine 3000 dilution medium without serum each well to a final concentration of $50 \mathrm{nM}$. Meanwhile, the non-silencing RNA was transferred in the same condition with merely lipo complex (Mock) and PBS (NC) as controls (all of the siRNA were synthesized by RuiBo Biotechnology Company, Guangzhou). The process was lucifugal. Candidate sequences of RNA oligos were listed in Table 1. Among them, the first one with the highest transfection effect was finally chosen for the subsequent experiment. Transfection was processed according to the manufacturer's instructions. Visible green FITC-siRNA fluorescence and quantitative Bmal1 mRNA extraction were prepared to test the efficacy of siRNA 48 hours later. Cells were harvested at the indicated time points and processed for further analysis. After transfection, cells were resuspended in regular culture medium and plated. Proteins of target pathway were analyzed by Western blot analysis using specific antibodies. Nf-kBp65 siRNA was a commercial product (CST, 6337S).

\section{Measuring hormone synthesis and sensitivity to $L H$ stimulation in vitro}

Culture supernatants from GCs or TCs monolayers were taken from individual wells to detect hormone levels $48 \mathrm{~h}$ after siRNA transfection with additional 12-h LH co-culture. After centrifugation at $2500 \mathrm{~g}$ at $4^{\circ} \mathrm{C}$ for 15 min, the supernatant was stored at $-80^{\circ} \mathrm{C}$ for hormone measurement. The concentrations of Estradiol ( $E_{2}$; KGE014, R\&D Systems), testosterone (T, RnD, KGE010), progesterone $\left(\mathrm{P}_{4}, \mathrm{EA}\right.$, Merck-Millipore, STTHMAG$21 \mathrm{~K}-02)$ and androstenedione (AND, LSBio, ELISAKitLS-F39181) were determined by ELISA using kits according to the manufacturer's protocols, respectively. A reported physiological concentration $(2.5 \mathrm{ng} / \mathrm{mL})$ of luteinizing hormone (LH) was added for $12 \mathrm{~h}$ to induce and maintain hormone secretion. Intra- and inter-assay precisions as described by coefficients of variations were $\mathrm{T}, \leq 3.1 \%$ and $\leq 6.3 \% ; A N D,<8 \%$ and $10 \%$. The detection limits of $\mathrm{E}_{2}, \mathrm{~T}, \mathrm{P}_{4}$ and AND were 12.3-3000 pg/mL, 0-10 ng/mL, $0.156-10 \mathrm{ng} / \mathrm{mL}$, and $0.156-10 \mathrm{ng} / \mathrm{mL}$, respectively.

\section{LY294002 treatment}

Post-siRNA transfection to Bmal1 impairment, LY294002 (Sigma, L9908-LMG) as a PI3K inhibitor, was $(200 \mu \mathrm{M})$ co-cultured with cells for $2 \mathrm{~h}$ at $37^{\circ} \mathrm{C}$ to suppress the phosphorylation of PI3K pathway.

\section{Quantitative real-time PCR analysis}

GCs and TCs were harvested and RNA was extracted using Trizol reagents according to manufacture instructions (Invitrogen). Quality and concentration

Table 1 siRNA sequences targeting Bmal1 mRNA.

\begin{tabular}{cl}
\hline Gene & siRNA target sequence $\left(5^{\prime}-3^{\prime}\right)$ \\
\hline Bmall & \\
1 & CCAAGGAAGTTGAATACAT \\
2 & GCTCTTTCTTCTGTAGAAT \\
3 & GCAAACTACAAGCCAACAT \\
\hline
\end{tabular}


of total RNA were checked using NanoDrop (Thermo Fisher Scientific). Samples were sequentially treated with RNase-free DNase I (TaKaRa) and Superscript II reverse transcriptase (Invitrogen) to remove contaminating genomic DNA and reverse transcribed into cDNA. qRTPCR was performed in triplicate according to protocols (Xu et al. 2015). The sequences of the primers for core circadian genes (Per1, Per2, Cry1, Cry2, Clock, Bmal1) and hormone synthesis related genes (Fshr, Lhcgr, Star, Cyp11a1, Hsd332, Cyp19a1 and Cyp17a1) were listed in Table 2. Transcript levels were normalized with that of the housekeeping gene Gapdh.

\section{Western blot analysis}

After centrifugation $\left(10,000 \mathrm{~g}, 15 \mathrm{~min}\right.$ at $\left.4^{\circ} \mathrm{C}\right)$, the supernatants were collected for protein analysis. The protein concentration was determined by Bradford protein assay. Western blot analysis was performed as previously described. Briefly, $50 \mu \mathrm{g}$ proteins from each sample were loaded onto an SDS polyacrylamide gel for electrophoresis and subsequently transferred to polyvinylidene fluoride membranes. The membranes were blocked with 5\% nonfat dry milk in PBS for an hour and incubated with a primary antibody against BMAL1 (1:200 dilution), AKT (1:1000 dilution), p-AKT (Thr 308) (1:2000 dilution), mTORC1 (1:1000 dilution), p-mTORC1 (Ser2481) (1:2000 dilution), S6K1 (1:1000 dilution), p70-S6K1 (Thr389) (1:2000 dilution), NfkBp65 (dilution 1:250 dilution), p-NfкB (Ser536) (1:250 dilution) overnight at $4^{\circ} \mathrm{C}$ (BMAL1, mTORC1, p-mTORC1, NfкBp65 and p-NfкB were purchased from Abcam; AKT, p-AKT, S6K1S and p70-S6K1 were purchase from CST Danvers, USA). Samples were then incubated for $1 \mathrm{~h}$ at room temperature with horseradish peroxidase-conjugated secondary antibodies (Santa Cruz, USA) (1:5000 dilution). Band intensities were visualized with chemiluminescence reagent (Millipore Corp.) by the BioMax film (Kodak) and then analyzed with Gel-Pro analyzer 4.0 software. $\beta$-Actin (Santa Cruz, USA) protein was utilized as a loading control.

\section{Bmal1 overexpression in theca cells}

A lentivirus overexpression vector with the Bmal1 and enhanced green fluorescent protein gene (eGFP) insert (LV5-eGFP-Bmal1, GenePharma, Shanghai, China) was constructed successfully and packaged into high-titer lentiviruses. The primary mice TCs were transfected with recombinant virosome or empty vector when the cell density was approximately $50 \%$. Expression of eGFP protein in each group was observed under an inverted fluorescence microscope at 5 days after transfection. The infection efficiency was confirmed by qRT-PCR.

\section{Immunoprecipitation (IP)}

All steps were performed at $4^{\circ} \mathrm{C}$ or on ice for immunoprecipitation after overexpression of BMAL1 in the primary theca cells.

Cells were washed twice with ice-cold PBS after gentle aspiration of culture media and lysed with lysis buffer containing protease inhibitor (Roche) for $10 \mathrm{~min}$. Whole-cell protein lysates were next centrifuged at $16,000 \mathrm{~g}$ for $10 \mathrm{~min}$ and normalized against a standard curve of BSA by Bradford assay. One milligram of total protein was washed with DynaBeads Protein G magnetic beads (Invitrogen) for $15 \mathrm{~min}$. Supernatants were transferred and incubated with $3 \mu \mathrm{g}$ of mice antiBMAL1 antibody (Abcam)/ $\mu \mathrm{g}$ of total protein at $4{ }^{\circ} \mathrm{C}$ overnight with constant agitation, or mice $\lg \mathrm{G}$ (Abcam) for negative control. A total of $30 \mu \mathrm{L}$ of pre-washed magnetic beads were added to per lysates for half an hour with constant agitation to capture the BMAL1combined protein complex. Immobilized fractions were washed at least three times with ice-cold lysis buffer, including protease and phosphatase inhibitors. All lysis

Table 2 Primer sequences for mice targeted steroidogenesis-associated genes and circadian clock genes.

\begin{tabular}{|c|c|c|}
\hline \multirow[b]{2}{*}{ Gene } & \multicolumn{2}{|c|}{ Primers sequence $\left(5^{\prime}-3^{\prime}\right)$} \\
\hline & Forward & Reverse \\
\hline Bmal1 & CCGTGGACCAAGGAAGTAGA & CTGTGAGCTGTGGGAAGGTT \\
\hline Star & GGGTGGATGGGTCAAGTTC & AGCACTTCGTCCCCGTTC \\
\hline Cyp11a1 & GTCCСАСТССТCAАAGCCAG & GAAGCACCAGGTCGTTCACAAT \\
\hline$H s d 3 \beta 2$ & GCСССТАСТGTACTGGCTTG & TCCCGATCCACTCTGAGGTT \\
\hline Cур17a1 & GCCCAAGTCAAAGACACCTAAT & GCCCAAGTCAAAGACACCTAAT \\
\hline Cyp19a1 & ACCTGGAGTAGGAGCCTTTACСТGC & CAGGTCCTGTTCAGCGGTTGGT \\
\hline Fshr & TGAGTCTGGCTATGCGTGTCTA & САССТСАTAACAGCСАAAC \\
\hline Lhcgr & GAGACGCTTTATTCTGCСАTCT & CAGGGATTGAAAGCATCTGG \\
\hline$N F \kappa B$ & TGATCCACATGGAATCGAGA & CAGGAAGGGATATGGAAGCA \\
\hline Clock & GGAGTCTCCAACACCCACAG & GGCACGTGAAAGAAAAGCAC \\
\hline Per1 & AGATCAACTGCCTGGACAGC & AGATCAACTGCCTGGACAGC \\
\hline Per2 & TGGCCTCСАTCTTTCACTGT & CAACACTGACACGGCAGAAA \\
\hline Cry1 & ССАTCСGСТGСGTCTATATCC & GAAGCAAAAATCGCСАССТGT \\
\hline Cry2 & AATTCCTTACTGGCCAGCCC & TTCTCGCCACAGGAGTTGTC \\
\hline Gapdh & TGTAGACCATGTAGTTGAGGTCA & AGGTCGGTGTGAACGGATTTG \\
\hline
\end{tabular}


buffer was instantly centrifuged at $16,000 \mathrm{~g}$ for $5 \mathrm{~s}$. The supernatant was collected, then $35 \mu \mathrm{L}$ of $2 \times$ SDS sample buffer was added, followed by boiling for $5 \mathrm{~min}$ at $95^{\circ} \mathrm{C}$.

The complex was separated on an SDS-PAGE gel, and transferred to PVDF membrane. Anti-BMAL1 input with use of anti-BMAL1 as the probe was showed in Lane 1 (BMAL1+cell samples). The enrichment in Panel 1 was sampling alone, and residual proteins in Panel 2 and 3 were jointly sampled. Lane 2 was performed with use of the anti-lgG antibody (Lane 2, IgG + cell samples) and Western blot of mere antibody IgG (Lane 3, mere IgG). Content in Panel 4 (of Lane 2) was sampled alone, and Panel 5 and 6 were sampled together, while the residuals in Lane 2 were sampled as whole. Proteins appearing in both Lane 2 and Lane 3 were identified as non-specific. After rolling out the non-specific ones from those proteins appeared at Lane 1, the specific proteins that direct interacted with BMAL1 were obtained. Abundance of membranes from BMAL1 immunoprecipitates were determined and categorized by mass spectrometric analysis (Q Exactive mass spectrometer, Thermo Fisher).

\section{Statistical analysis}

Results from Western blot were quantified with the ImageJ software. Statistical analysis was performed by applying GraphPad Prism (version 5.0) and Student's t-test. For comparison between two groups, a one-way ANOVA was performed followed by Dunnett's correction. Values of $P<0.05$ were considered significant and indicated by asterisks in the figures.

\section{Results}

\section{Deprivation of Bmal1 impaired luteal function in vivo}

We first investigated the change of progesterone levels at different time points post-PMSG/HCG injection in Bmal1 knockout mice (Fig. 1A). Serum progesterone level peak was shown at $36 \mathrm{~h}$ following PMSG/HCG treatment in Bmal1-/- females, evidently advanced to the WT females which showed the progesterone peak $12 \mathrm{~h}$ later. The peak progesterone level was statistically reduced to $18.4 \pm 5.6 \mathrm{ng} / \mathrm{mL}$ of Bmal1 knockout females as compared to $36.2 \pm 7.7 \mathrm{ng} / \mathrm{mL}$ of WT ones $(P<0.01)$. Serum estradiol level declined progressively overtime after luteinization within $72 \mathrm{~h}$ in the two genotypes (Fig. 1B). The estradiol concentrations were $37.3 \pm 8.0$ and $18.9 \pm 6.1 \mathrm{pg} / \mathrm{mL}$ of Bmal1-/- mice at $24,48 \mathrm{~h}$, respectively, significantly lower than $56.1 \pm 10.3$ and $30.7 \pm 11.0 \mathrm{pg} / \mathrm{mL}$ of WT at the same time points $(P=0.01, P=0.03)$. Thereafter, serum $\mathrm{E}_{2}$ rose in advance in Bmal1-/- ones, reaching to $28.4 \pm 4.4 \mathrm{pg} / \mathrm{mL}$ at 96 $h$, while the $E_{2}$ remained at a lower level of $17.2 \pm 5.7$ $\mathrm{pg} / \mathrm{mL}$ in WT $(P=0.03)$.
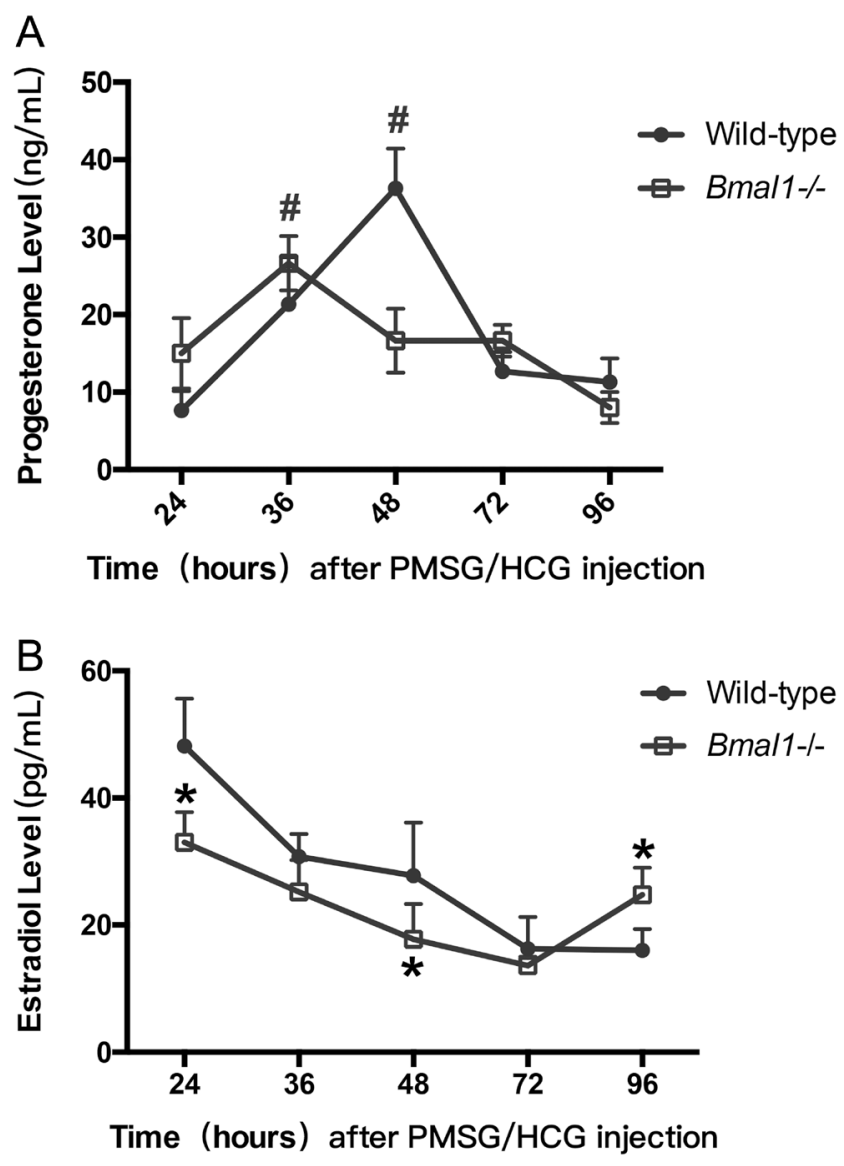

Figure 1 Luteal profiles of serum hormone levels through out 4 days post-PMSG/HCG injection. Hormones were measured by ELISA kits. Each value represents the mean \pm S.D. (A) Progesterone levels. \#Peak value comparison between Bmal1-/- and WT female mice with $P<0.05$ or less. (B) Estradiol levels. *Comparison between Bmal1-/and WT at corresponding labelled time point with $P<0.05$ or less. $n=3$ females at 8 weeks old per time point in each group.

\section{Bmal1 knockdown promoted in vitro follicle cell proliferation}

TCs exhibited fibroblast-like, long fusiform or anomalistic triangular shapes, while GCs looked like cobblestones with polygonal or cuboidal shapes (Fig. 2A). Cells were further identified by Cytochrome P450, family 17 , subfamily $A$, polypeptide 1 (CYP17A1), known to be specifically expressed in TCs, and the GCs-specific marker Follicle-Stimulating Hormone Receptor (FSHR). As shown in Fig. 2B, the majority isolated TCs remained CYP17A1 positive and FSHR negative, while GCs showed the opposite results. Additionally, total protein from the isolated TCs and GCs were extracted, respectively, for Western blotting of CYP17A1 and FSHR. As shown in Fig. 2C, FSHR was expressed at very low levels in the TCs, while CYP17A1 was expressed at high levels. Conversely, FHSR, but not CYP17Aa was expressed abundantly in the GCs. 
A

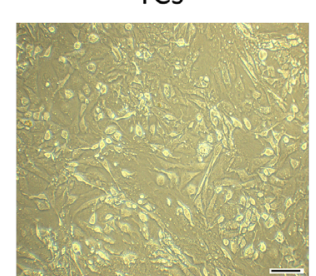

GCs

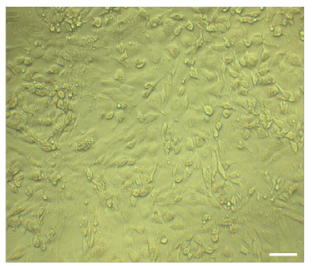

B

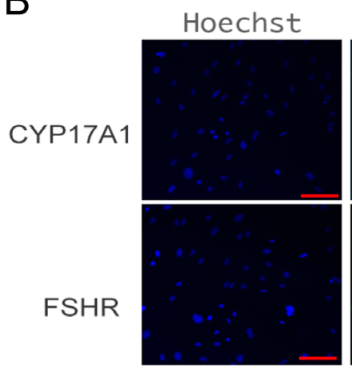

D

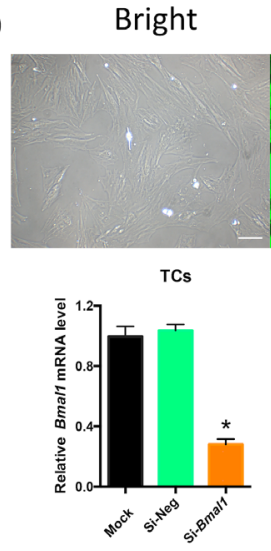

Florescent
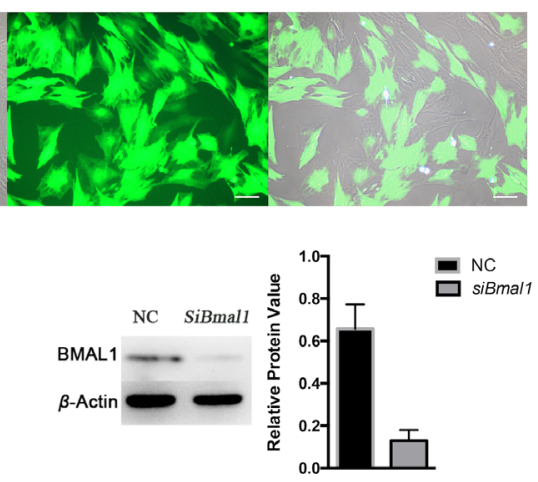

F

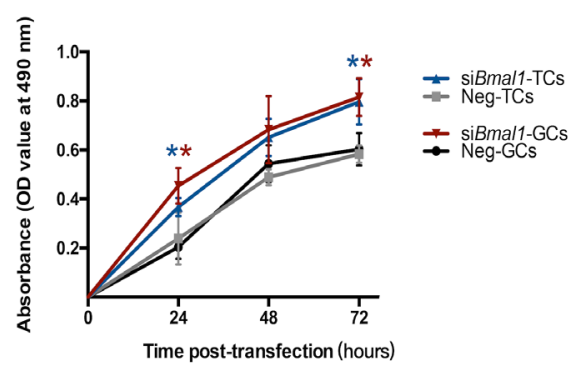

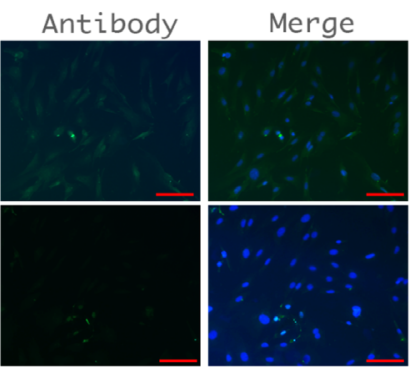

TCs
C
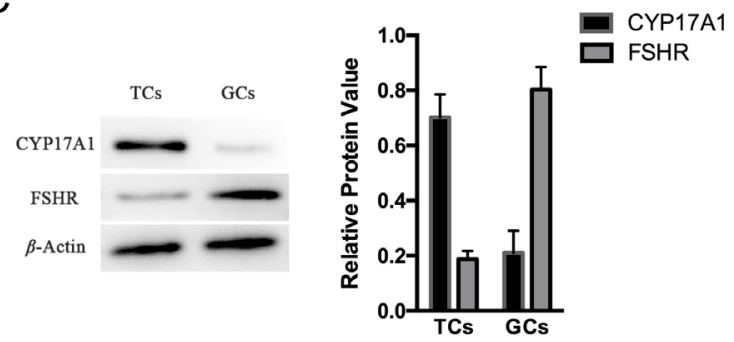

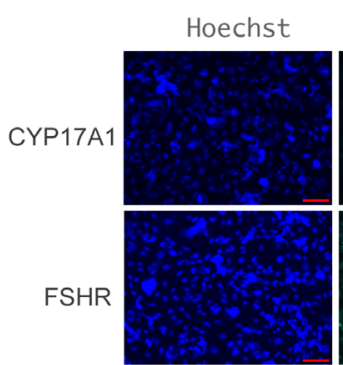

E

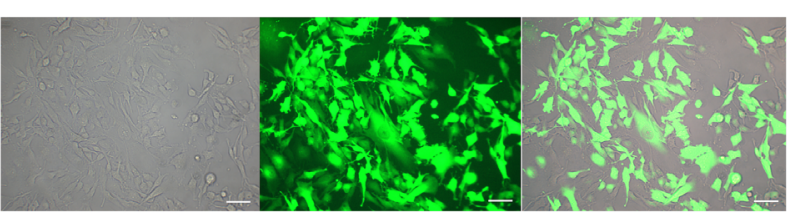

GCs

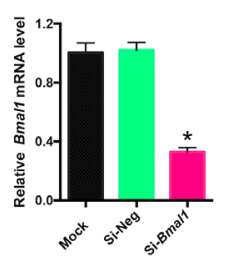

G

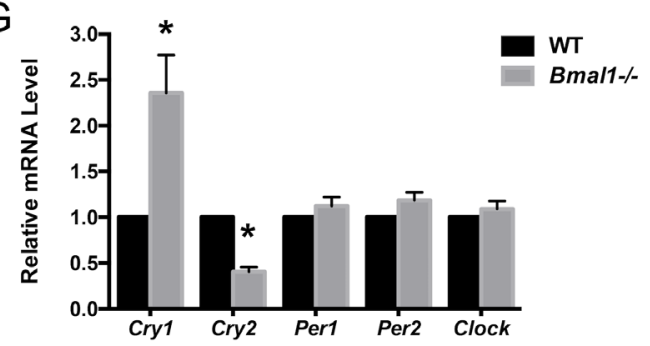

Figure 2 Follicle cells proliferation and transcriptions of other core circadian genes post-siRNA-Bmal1 transfection. (A) Cells morphology. Fusiform-aligned TCs and cobblestone-like GCs (200x, Scale Bar $=100 \mu \mathrm{m})$. (B) Immunofluorescence staining of CYP17A1 and FSHR observed under fluorescence microscope $(400 x$, Scale Bar $=50 \mu \mathrm{m})$. Most isolated TCs remained CYP17A1 positive and FSHR negative, while immunofluorescence staining of CYP17A1 and FHSR showed opposite in GCs. (C) Relative protein levels of CYP17A1 and FSHR by Western blot (left) and corresponding band intensities (right). (D) and (E) Transfection efficiency of TCs (D) and GCs (E). Transfected cells were signaled by green fluorescence (upper) and knockdown efficiency in isolated cells (below) was ascertained by qRT-PCR analysis of Bmal1 mRNA. Both Mock (nonsiliencing) and si-Neg (empty vector transfected) were controls. ${ }^{*} P<0.05$ vs the si-Neg group. (F) Growth curve according to OD value after siRNA-Bmal1 transfection detected by MTS assays. Bmal1 interference accelerated both isolated GCs and TCs growth significantly. (G) mRNA expression of core circadian genes (Cry1, Cry2, Per1, Per2, clock) in mice ovaries quantified by qRT-PCRT, WT mice. Bmal1-/-, mice genotyped with whole bmal1 knockout. ${ }^{*} P<0.05$ or less. Data are presented mean \pm S.D. of three independent determinations. ${ }^{*} P<0.05$ or less vs the Neg (control) group. TCs, theca cell. GCs, granulosa cells. 
Bmal1 transcription rates were decreased to $27.34 \pm 5.92 \%$ in TCs and $32.21 \pm 4.40 \%$ in GCs, respectively, after siRNA transfection when compared to the controls by qRT-PCR $(P<0.01)$ (Fig. 2B). The transfection efficiency was confirmed by Western blot (Fig. 2D for TCs and Fig. 2E for GCs).

MTS assay was conducted to evaluate cells proliferation $72 \mathrm{~h}$ post-transfection. Growth curve was drawn according to OD value. As presented in Fig. 2F, cell growth of both TCs and GCs significantly accelerated after Bmal1 siRNA transfection, as compared to the controls.

Considering feedback loops and compensated interactions between Bmal1 and other clock genes, transcriptional levels of core circadian genes such as Cry1, Cry2, Per1, Per2, and Clock were tested in

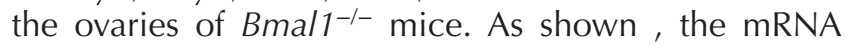
expression of Cry2 was significantly decreased, while Cry 1 was significantly increased in ovaries from Bmal1 knockout mice. However, transcriptional expressions of clock, Per1 and Per2 were unaffected (Fig. 2G).

\section{Suppression of Bmal1 impaired secretion of steroid hormones}

To further investigate the role of $\mathrm{Bma} / 1$ on luteal hormone secretion, we measured steroid hormone concentrations in the culture supernatants of cells subjected to $\mathrm{LH}$ stimulation for $12 \mathrm{~h}$. Cells transfected with empty vector consisted of the sham control group.
In TCs, both AND and T concentrations were significantly lower in the Bmal1-siRNA group (AND $5.51 \pm 1.39 \mathrm{ng} / 10^{5}$ cell, T $4.41 \pm 1.87 \mathrm{ng} / 10^{5}$ cell) than those in the controls (AND $7.85 \pm 1.46 \mathrm{ng} / 10^{5}$ cell, T $7.15 \pm 1.10 \mathrm{ng} / 10^{5}$ cell $)(P=0.006$ and 0.033 , respectively). Meanwhile, $\mathrm{P}_{4}$ levels were presented with down trend post-transfection (Fig. 3A). As presented in Fig. 3B, suppression of Bmal1 impaired $E_{2}$ and $P_{4}$ synthesis in GCs $\left(E_{2}: 1.48 \pm 0.56\right.$ vs $3.02 \pm 0.47 \mathrm{pg} / 10^{5}$ cell, $P=0.009 ; P_{4}: 5.82 \pm 1.01$ vs $2.02 \pm 0.73 \mathrm{ng} / 10^{5}$ cell, $P=0.003$ ).

A subset of genes related to steroidogenesis was further investigated after Bmal1 siRNA transfection. In the Bmal1-siRNA group, the transcriptional level of Lhcgr in TCs significantly decreased (Fig. 3C, left), while no change was detected in GCs (Fig. 3D, left). However, the differences of Lhcgr levels in TCs between Bmal1siRNA group and the control were vanished after $\mathrm{LH}$ stimulation, which raised comparability within groups (Fig. 3C, left). For other steroidogenesis-associated genes, in TCs, the mRNA levels of Star, Hsd3ß2, and Cyp17a1 in the Bmal1-siRNA group were significantly lower than control group after LH stimulation, except Cyp11a1 (Fig. 3C, right). As in GCs, the mRNA levels of Star, Hsd332, and Cyp19a1, except FSHR, in the transfected group were significantly lower than the control (Fig. 3D, right). The reduced transcriptional levels of Star, Cyp19a1, Hsd3ß2, and Cyp17a1 were in
A
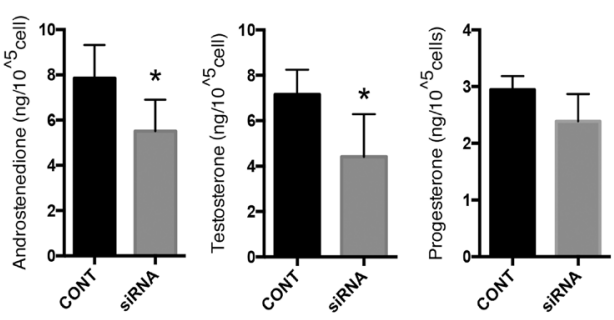

C
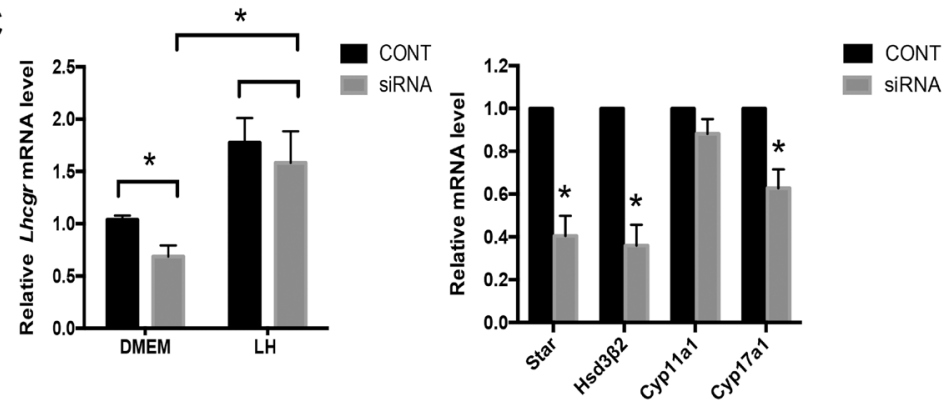

B
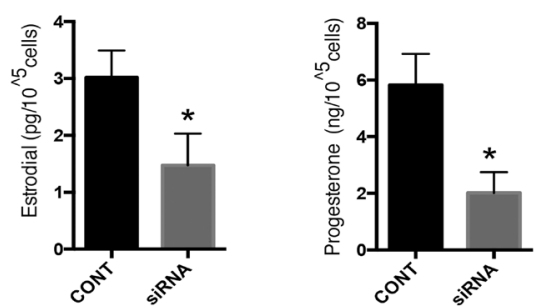

$\mathrm{D}$

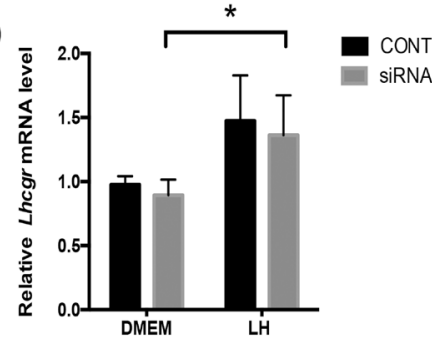

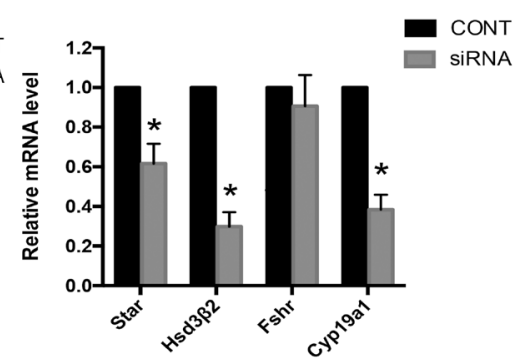

Figure $3 \mathrm{Bmal1}$ downregulation decreased luteal hormones synthesis and impaired mRNA transcriptions of steroidogenesis-associated genes in lutenized follicle cells. (A) Androgen and progesterone concentrations in TCs' supernatants. (B) Progesterone and estradiol levels in GCs' supernatants. Bmal1 interference deteriorated $\mathrm{P}_{4}$ and $\mathrm{E}_{2}$ production. (C) Left, TCs' Lhcgr mRNA levels. Right, mRNA transcriptions of other targeted steroidogenesis-associated genes in TCs. (D) Left, GCs' Lhcgr mRNA levels. Right, mRNA transcriptions of other targeted steroidogenesisassociated genes in GCs. The relative mRNA expression was normalized to Gapdh and expressed as relative to CONT. siRNA, group of cells transfected with siRNA against Bmal1. CONT, cells transfected with siRNA with empty vector as controls. LH, cell cultured with LH supply additionally for $12 \mathrm{~h}$. DMEM, cells cultured with regular culture media containing DMEM. mRNA levels of target genes in cells were quantified by qRT-PCR using their specific primers. Data are presented mean \pm S.D. of five independent determinations. ${ }^{*} P<0.05$ or less vs the control group. 
A

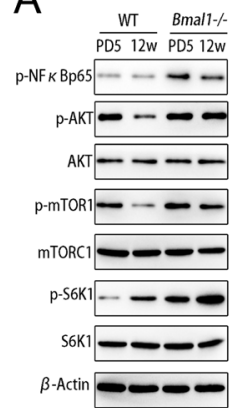

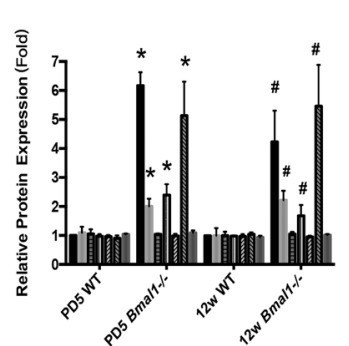

B

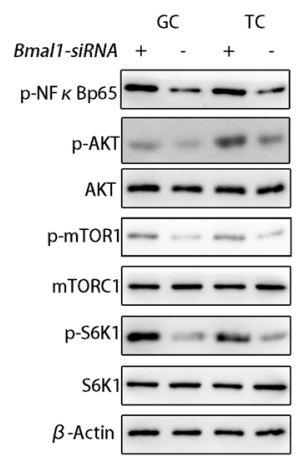

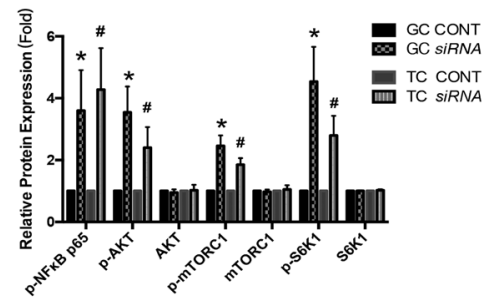

Figure 4 Bmal1 loss activated phosphorylation of NFkB/PI3K pathway. (A) Ovarian protein levels and quantitation assessment of Bmal1knockout mice by Western blot. Left, a typical Western blot. Right, bands were densitometrically qualified and the intensities shown were normalized to $\beta$-Actin, relatively to WT control. PD 5, post-natal 5 days. Bmal1-/-, mice genotyped with whole bmal1 knockout. ${ }^{*} P<0.05$ or less vs PD5 WT; $\# P<0.05$ or less vs 12 week WT. Data are presented mean \pm S.D. of three independent experiments. (B) Protein levels and quantitation assessment of Bmal1-knockdown GCs and TCs with siRNA transfection. Left, a typical Western blot. Right, bands were densitometrically qualified and the intensities shown were normalized to $\beta$-actin, relatively to CONT of corresponding cell types. GC, granulosa cell. TC, theca cell. siRNA, group of cells transfected with siRNA knockdown Bmal1 transcriptions. CONT, cells transfected with siRNA with empty vector as controls. ${ }^{*} P<0.05$ or less vs GC CONT. $\# P<0.05$ or less vs TC CONT. All data were the mean \pm S.D. of three independent experiments where all the samples were repeated in thrice.

accordance with decreased secretion of $\mathrm{E}_{2}$ and down trend of $\mathrm{P}_{4}$.

\section{Bmal1 interference activated phosphorylation of PI3K/NfאB pathway}

Since it has been reported that Bmal1 knockout activated phosphorylation of the PI3K/AKT/mTORC1 pathway (Acosta-Martínez 2011, Guo \& Yu 2019), we supposed that it may work as an attractive candidate closely involved in steroidogenic regulation. $\mathrm{Nf \kappa B}$, recently proved as a mediator of inducible transcriptional response to circadian signaling, was also reported to have the ability to cross-talk with the PI3K/AKT/mTORC1 (Meng et al. 2002, Ghoneum \& Said 2019). Based on these evidences, we hypothesized that Bmal1 might orchestrate luteal steroidogenesis through PI3K/AKT/ mTORC1/NfkB pathway. To prove our hypothesis, we examined the phosphorylated proteins of the implicative pathway under the condition of Bmal1 complete loss in vivo and partially knockdown in vitro. Our results showed that global Bmal1 deletion in vivo resulted in activation of $\mathrm{PI} 3 \mathrm{~K} / \mathrm{AKT} / \mathrm{mTORC} 1$ phosphorylation pathway and simultaneously enhanced $\mathrm{Nf \kappa B}$ phosphorylation at Ser536 in integrated ovary (Fig. 4A).

To strength our findings, phosphorylation of Akt (Thr 308), mTORC1 (Ser 2481), downstream S6K1 at Thr389 together with $\mathrm{Nf \kappa B}$ at Ser 536 were all detected in both isolated TCs and GCs after Bmal1-siRNA transfection. Our results showed that phosphorylation of both pathway PI3K/AKT/mTORC1 and NfKB was activated, which was in accordance with the changes observed in vivo when Bmal1 was completely deprived. These results confirmed that Bmal1 impairment leads to overactivation of $\mathrm{PI} 3 \mathrm{~K} / \mathrm{NfKB}$ signaling phosphorylation in luteinzed TCs and GCs (Fig. 4B).

\section{PI3K/NfאB interacted with negative feedback to BMAL1 on in isolated TCs}

To further explore the mechanism under PI3K pathway, isolated TCs was furtherly exposed to LY294002, a selective PI3K inhibitor, post-Bmal1-siRNA transfection with LH stimulation. Cellular transcription levels and phosphorylation of $\mathrm{NfkB}$ as well as supernatant hormone levels of cultured TCs were examined.

As shown in Fig. 5A, LY294002 intervention significantly rescued AND and $T$ synthesis, together with the elevated trend of $\mathrm{P}_{4}$ level, under conditions post-Bmal 1 interference. In accordance with hormonal findings, expression levels of Hsd3 32 and Lhcgr rose with significant differences post-LY294002 intervention while Star remained unaffected. Paradoxically, Cyp17a 1 was furtherly reduced (Fig. 5B).

Meanwhile, Bmal1 exerted a negative feedback on mRNA transcription of $\mathrm{Nf \kappa B}$ (Fig. 5C). Blockade of PI3K signaling suppressed total protein levels which were enhanced by Bmal1 knockdown, as well as phosphorylation of NfkB p65 at Ser536 (Fig. 5D).

\section{Evidences of direct negative interaction between $B M A L 1$ and NfאB}

To explore clues of direct interaction between BMAL1, mTOC and $\mathrm{Nf \kappa B}$, we characterized proteins in nucleus and cytosol of unsynchronized TCs that co-precipitated with BMAL1 through SDS-PAGE (Fig. 6A) followed with mass spectrometry (MS). Primary comparison was conducted between panels from IgG + cell samples and IgG to identify and roll out duplicated proteins, after which the exclusive proteins that co-precipitated with BMAL1 were retrieved from Lane 1. Among candidate proteins, only $\mathrm{Nf \kappa B}$ p65 (RelA), a subunit of $\mathrm{Nf \kappa B}$, was identified. Other retrieved peptides directly interacted 

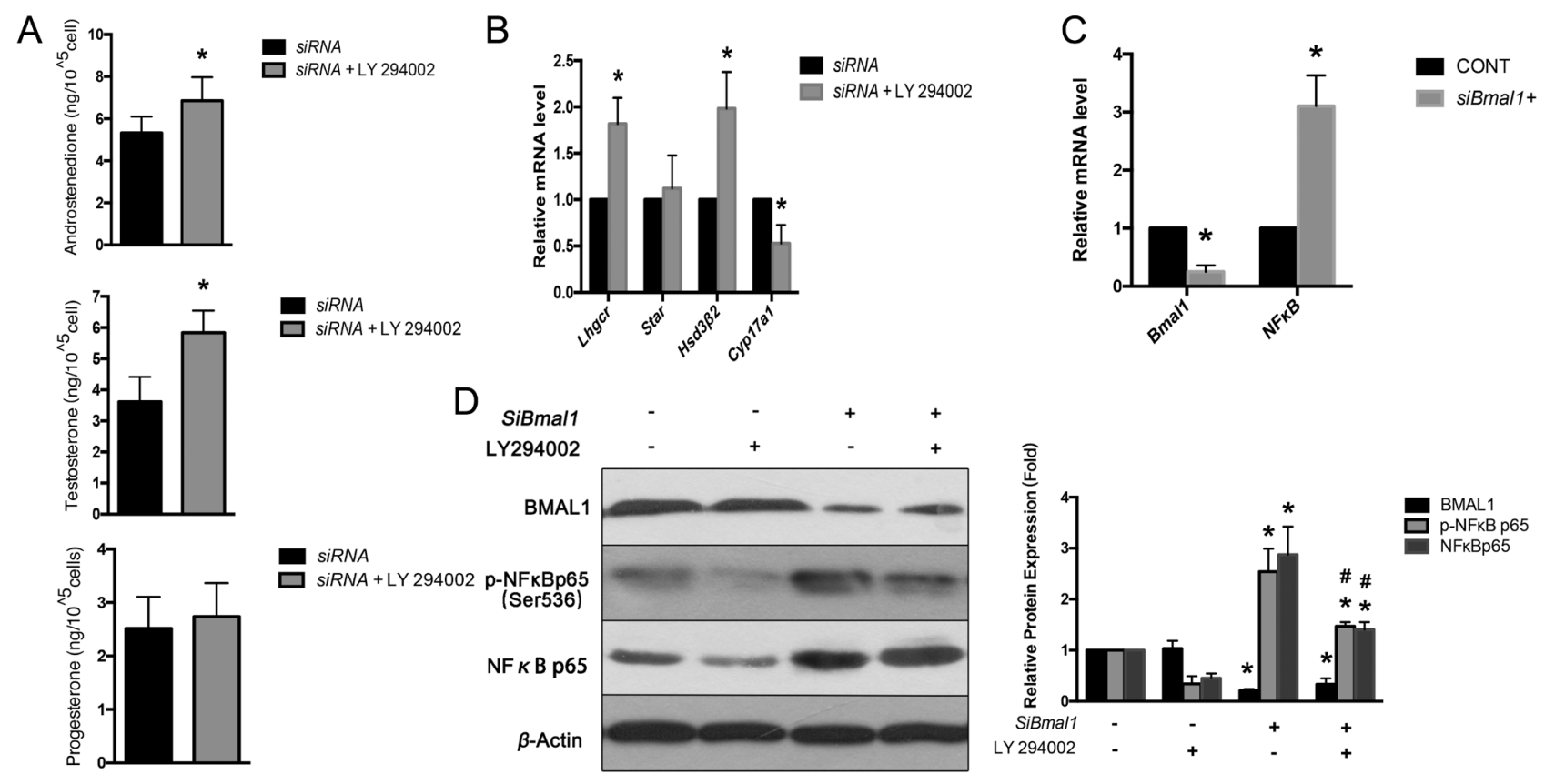

Figure 5 Effects of PI3K specific inhibitor LY294002 on hormone synthesis and underlying NFkB pathway of isolated ovarian theca cells. (A) Androgen and progesterone concentrations in supernatant culture media. (B) mRNA levels of target genes after Bmal1 siRNA (siRNA) transfection normalized to Gapdh. siRNA, group of cells transfected with siRNA against Bmal1 with intact solvent co-cultured as control. mRNA levels of target genes in cells were quantified by qRT-PCR using their specific primers. Data are presented mean \pm S.D. of five independent determinations. ${ }^{*} P<0.05$ or less vs siRNA. (C) Bmal1 downregulation enhanced mRNA levels of $N F \kappa B$. (D) Bmal1 knockdown enhanced total NFKB p65 protein expression and activated phosphorylation of NFKB p65 at Serine-536, which could be suppressed by LY 294002. Left, a typical Western blot. Right, bands were densitometrically qualified and the intensities were normalized to $\beta$-actin, relatively to WT control. $* P<$ 0.05 or less vs corresponding protein in siBmal1-/LY294002-. \#P<0.05 or less vs corresponding protein in siBmal1+/ LY294002-. siBmal1-, cells transfected with empty vector without Bmal1 interference. siBmal1+, siRNA transfection to interfere Bmal1. LY 294002, a PI3K specific inhibitor. LY 294002-, cells treated with mere solvent. LY 294002+, cells co-cultured with solvent dissolved with LY $29400250 \mu \mathrm{M}$ for a 2-h incubation at $37^{\circ} \mathrm{C}$. Bars represented as mean \pm S.D. of three independent determinations.

with BMAL1 corresponding to annotated mouse proteins were summarized together in Supplementary Excel.

Next, we verified the direct interaction between Bmal1 and NfkB p65 by Bmal1 enhancement experiment in TCs. When Bmal1 was overexpressed, $N f_{\kappa} B$ mRNA transcription, corresponding translated proteins and its subunit Rel $\mathrm{A}^{\prime}$ phosphorylation were consistently decreased (Fig. 6B and C). Combined with our previous results from Bmal1 knockdown and knockout experiments (Fig. 4A and B), which showed protein levels of phosphorylated NfkB p65 was upregulated, we proved the negative feedback between Bmal1 and $N f_{\kappa} B$ p65. It was further verified in $N f_{\kappa} B$ p65 knockdown experiment, as an obvious increase of BMAL1 protein levels was detected when $N f_{\kappa} B$ p65 was interfered (Fig. 6D). Additionally, to confirm mediated role of $\mathrm{Nf \kappa B}$ RelA regarding Bmal1-induced AKT phosphorylation, Western blotting experiments explored the levels of $\mathrm{p}$-AKT. As expected, protein levels of $\mathrm{p}$-AKT was presented to be inhibited in accordance with the changes of NfKB p65 (Fig. 6D). The cellular mechanism regarding Bmal1 governed NFKB/PI3K pathway in steroidogenesis regulation in TCs was summarized in the schematic diagram (Supplementary
Fig. 1, see section on supplementary materials given at the end of this article).

\section{Discussion}

During the past decades, substantial evidences have come to light that ovarian clock orchestrates and synchronizes reproductive physiological events such as follicle aggregation, ovulation and implantation. However, the impact of cellular self-sustaining endogenous circadian rhythms on luteal function is less well studied. The present study showed that deprivation of Bmal1, as a molecular-switch of the circadian oscillation, altered luteal phase profile in Bmal1 null mice. Correspondingly, luteal steroidogenesis was attenuated after Bmal1 interference, as shown in isolated GCs and TCs, respectively. Molecularly, a novel role of Bmal1, which negatively interplayed with PI3K/ $\mathrm{Nf \kappa B}$ in theca cells with respect to regulation of luteal steroidogenesis, was proclaimed.

Bmall exerts its function mainly through central clock, which was proved in Bmal1 knockout mice. However, previous studies have demonstrated its peripheral role in ovary, for ovarian-specific knockout of Bmal1 

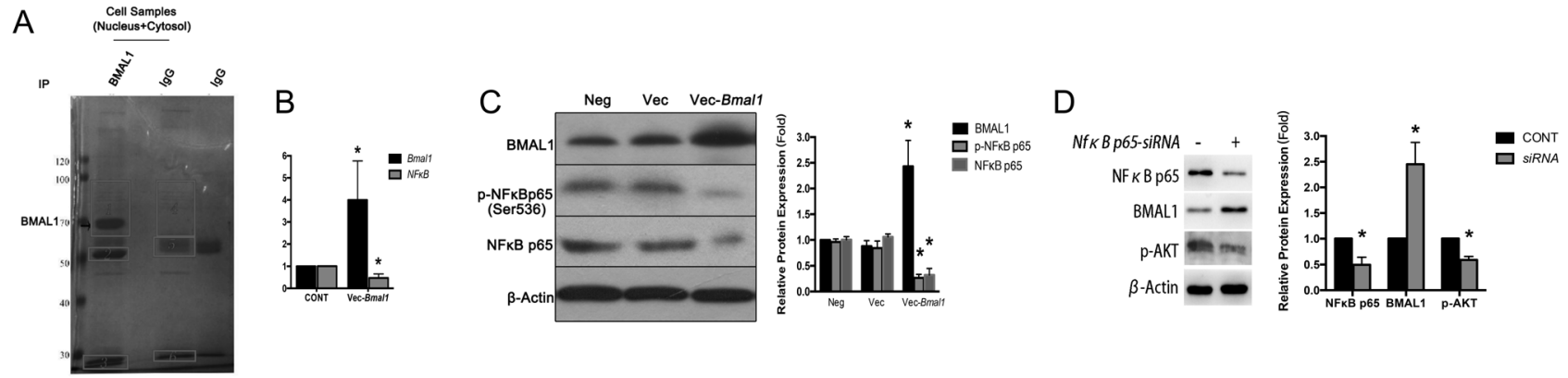

Figure 6 Immunoprecipitations and feedback loops verification of interactions between BMAL1 and NFkB. (A) Immunoprecipitations to characterize proteins that co-precipitated with BMAL1 followed by mass spectrometry in primary-cultured mice theca cells. (B) and (C) Effect of Bmal1 over-expression on the transcription and protein level of NFKB in mice theca cells. (B) Expression of NFkB quantified by qRT-PCR. (C) Left, a typical Western blot. Right, bands were densitometrically qualified and the intensities shown were normalized to $\beta$-actin, relatively to Vec-BMAL1 as control. ${ }^{*} P<0.05$ or less vs corresponding protein in Vec. Neg, cells without transfection as negative control. Vec, cells transfected with empty vector as sham control. Vec-Bmal1, transfected with vector to overexpress Bmal1. Bars represented as mean \pm S.D. of three independent determinations. (D) Effects of $N f_{\kappa} B$ p 65 knockdown on BMAL1/PI3K pathway in theca cell. Left, a typical Western blot. Right, bands were densitometrically qualified and the intensities shown were normalized to $\beta$-actin, relatively to $N f_{\kappa} B \quad p 65$-siRNA- as control. ${ }^{*} P<$ 0.05 or less vs corresponding protein in $N f_{\kappa} B$ p65-siRNA-. Nf $f_{\kappa} B$ p65-siRNA-=CONT, cells transfected with empty vector without $N f_{\kappa} B$ p65 interference. $N f_{\kappa} B$ p 65 -siRNA+=siRNA, siRNA transfection to interfere NFkB p65 subunit expression. Bars represented as mean \pm S.D. of three independent determinations.

compromised progesterone synthesis, and in vitro study using Bmal1 downregulation GCs further confirmed the result (Chen et al. 2013b, Liu et al. 2014). However, change of luteal phase profile after Bmal1 deprivation remained obscure. Here, we showed that global Bmal1 deprivation could evidently alter mice luteal phase profile, characterized by an advanced peak of $\mathrm{P}_{4}$ and minor amplitude of $E_{2}$, indicating possible luteal phase defect. It was noteworthy that an advanced $E_{2}$ level rose at $96 \mathrm{~h}$, a time-point corresponding to the late stage of luteinization followed by a new round of estrus. This metestrus $E_{2}$ priming let us reason that it might be a foreboding of early recruitment of antral follicles for the next round of ovulation, leading to early-onset of ovarian aging detected from female mice with impaired or null Bmal1 expression (Liu et al. 2014). Considering endocrine function of corpus luteum involving not only Bmal1 but also Per2 (Shimizu et al. 2011, Fahrenkrug et al. 2006), another core clock gene which was proved to interact with Bmal1 in a transcription-translation feedback loop but in a displacement-type manner (Chiou et al. 2016), we tested the transcriptional level of Per2. Nevertheless, no change of Per2 expression was found in ovaries of Bmal1 knockout female mice, which excluded the possible impact of Per2 in the current study.

To clarify peripheral role of Bmal1 in the ovary, we used Isolated TCs and GCs, each has independent characteristics with respect to steroidogenesis. Meanwhile, in vitro culture created an environment with no more pulsatile and rhythmic endocrine regulation from hypothalamus and pituitary. Although a bulk of evidences has proved that Bmal1 was involved in hormone synthesis of ovarian steroid cells, majority focused on GCs (Alvarez et al. 2008, Sen \& Hoffmann 2020). Given GCs andTCs were born to be with distinctive cellular characteristics and governed underneath diverse endocrine cues, we furtherly explored cell-specific effects raised from $\mathrm{Bmal} 1$ on luteal steroidogenesis. As shown here, evidently impaired AND and T synthesis with a downward trend of $\mathrm{P}_{4}$ secretion was detected in TCs. Meanwhile, GCs encountered a significant decreased level of $E_{2}$ secretion, accompanied by a fall of $\mathrm{P}_{4}$ in supernatant after partial Bmal1 loss.

The underlying mechanism of how Bmal1 modulate the steroidogenesis during luteinization in different type of luteal cells remains unclear. Acting through ovarian clock-controlled genes were proved to be an effective way (Shearman et al. 2000), since different clockcontrolled elements were detected at the promoters of genes involved in steroidogenesis (Chen et al. 2013b). In the present study, siRNA-mediated knockdown of Bmal1 caused downregulation of Lhcgr in TCs, which supported existing viewpoint that $\mathrm{L}$ chgr was regulated by circadian clock (Lisa Gilioli et al. 2017, Wang et al. 2017). Interestingly, exogenous LH stimulation could completely rescue $\mathrm{Lhcgr}$ expression in isolated Bmal1interferred TCs. In this respect, it might answer why TCKO mice presented with an indistinctive phase shift and abolished rhythm of Lhcgr but not a whole loss of its expression, since compensation in TCs might be achieved from endogenous LH secretion in vivo (Mereness et al. 2016). However, this impaired-rescued process only worked in TCs other than GCs, as our finding showed that Lhcgr of GCs was left impervious after Bmal1 partially deprivation, consistently with the reported phenotype that GCKO mice persisted with Lhcgr diurnal circadian rhythm (Mereness et al. 2016). This phenomenon might be attributed to cell-specific characteristics, although we could not exclude the possibility due to incomplete deprivation of Bmal1 transcriptions, whose residuals 
were capable enough to sustain considerable sensitivity to LH stimulation. Physiologically, TCs interact directly with ovarian stroma and receiving signals straightforward from peripheral circulation system and the master suprachiasmatic nucleus (SCN) of the hypothalamus (Young \& McNeilly 2010). Since GCs locate under the surrounding of TCs, it is reasonable to speculate that intimate cellular interactions worked between GCs and TCs in in vivo models may compensate the deficiency of clock function in GCs, leading to the negative result in GCKO mice.

It is worthy to point out that Bmal1 may exert noncircadian related functions (Liang et al. 2013), which is regarded as unique cellular functions distinct or independent from its role in maintaining circadian oscillation (Musiek et al. 2013). Although the exact mechanism remains unclear, certain evidences have addressed its non-circadian functions (Yang et al. 2016), for example, Bmal1 knockout mice are characterized with aging properties and metabolic abnormalities, while knockout mice of other clock genes in the core circadian feedback loops, such as Cry $1 /$ Cry2 or Per1/Per2 double knockouts, did not present with the same phenotype (Dierickx et al. 2018).

As shown in our study, Bmal1 knockdown activated phosphorylation of $\mathrm{PI} 3 \mathrm{~K} / \mathrm{Nf} \kappa \mathrm{B}$ pathway, reducing androgen biosynthesis and transcriptional levels of Hsd3 32 and Lhcgr. Blockage of PI3K/NfkB by selective $\mathrm{PI} 3 \mathrm{~K}$ inhibitor rescued expressions of $\mathrm{Hsd} 3 \mathrm{\beta} 2$ and $\mathrm{Lhcgr}$ but exerted no impact on Star levels, which sustained the existed perspective that Star might be strictly and directly under circadian control rather than PI3k/ $\mathrm{Nf \kappa B}$ signaling. As for Cyp17a1, other pathway might be participated under Bmal1 control, which deserved further exploration (Baburski et al. 2016).

It remains elusive how Bmal1 acted on PI3K pathway. By mass spectrometry in our study, no protein subunit related to $\mathrm{mTOC}$ and $\mathrm{PI} 3 \mathrm{~K}$ was found, indicating that none direct intermediary anchored BMAL1 to mTOC and $\mathrm{PI} 3 \mathrm{~K}$, which was in accordance with the results of Wu et al. (2019). However, a subunit of NfkB, RelA (also known as NFkB p65) was screened out, which was proposed to anchor as a mediator where BMAL1 exerted regulation to PI3K pathway in a direct manner. The $\mathrm{Nf} \kappa \mathrm{B}$ complex was inclined to be activated during aging process (Salminen et al. 2008). Till now, only RelA and RelB from NFKB family have been proved to have direct interactions with BMAL1. Concerning how Bmal1 interacted with $\mathrm{Nf \kappa B}$, to date, very limited evidences were found and none was involved in follicle cells. Here, we proved a negative feedback loop between BMAL1 and $\mathrm{Nf} \kappa \mathrm{B}$ p65, as indicated by converse changes of one to another in the gain and loss experiments, which was consistent with the findings in human aortic endothelial cells by Mengru et al. (Xie et al. 2020). However, in mouse embryo fibroblasts (MEFs), the BMAL1-CLOCK complex was detected to directly combine with NFkB p65 subunit, and transcriptionally active form of this specific RelA subunit was proved to be consisted with the dimer overexpression, especially CLOCK dependence (Spengler et al. 2012), which elucidated a converse change to our findings. Another subunit RelB of NFKB was found to physically interact with the circadian activator BMAL1 in the presence of CLOCK to repress targeted circadian gene expression (Bellet et al. 2012).

Previously findings suggested that $\mathrm{NFKB}$ was a downstream of PI3K mediated by AKT (Bai et al. 2009), however, latest studies pointed out that there should be a cross-talk between these two cellular signaling (Hussain et al. 2012). In our study, by interference the subunit RelA of NFKB and application of PI3K specific inhibitor LY294002, we originally proved a positive cross-talk between NFKB p65 and PI3K/AKT pathway in ovarian TCs mechanistically and functionally, as the luteal steroidogenesis of TCs was correspondingly explored. The precise mechanism on what kind of molecular interaction or modification between Bmal1-induced RelA and PI3K/AKT requires further study.

This study has several limitations. First, we only did Bmal1 knockdown experiment using siRNA. TCs with Bmal1 knockout by Crisp-cas9 may give us more convincing results, although technically, it is difficult as no stabilized-passaged TC line strain was available. Moreover, if a rescue experiment covering Bmal1 recover was conducted in vitro, our conclusion might be more conclusive. Lastly, we could not differentiate whether phenotypic changes of TCs were due to disruption of circadian rhythms or the alterations of non-circadian related function of Bmal 1 in the current study, since the rhythm of Bmal1 in isolated cells was merely weakened but not completely abolished.

To sum up, our study elucidated the significant role of the core circadian gene Bmal1 in luteal steroidogenesis, mainly interacting negatively but directly with PI3K/ $N f_{\kappa} B$ pathway. Our results highlighted the importance of circadian control on reproductive function, which definitely deserves more profound studies in the future.

\section{Supplementary materials}

This is linked to the online version of the paper at https://do i.org/10.1530/REP-20-0340.

\section{Declaration of interest}

The authors declare that there is no conflict of interest that could be perceived as prejudicing the impartiality of the research reported.

\section{Funding}

This work was supported by National Natural Science Foundation of China (Grant No. 81771588, Youth Program: 
Grant No. 81801412), Guangdong Basic and Applied Basic Research Foundation (2019A1515010991) and the National Basic Research Program of China (973 Program, Grant No. 2012CB947604).

\section{Author contribution statement}

Xu Yanwen, Wang Yizi and Zhou Canquan designed the research. Wang Yizi, Chen Minghui, Xu Jian, Liu Xinyan and Duan Yuwei performed the specific research. Xu Jian, Liu Xinyan and Duan Yuwei analyzed the data. Xu Yanwen and Wang Yizi wrote the paper. All authors read and approved the final manuscript.

\section{Acknowledgements}

The authors would like to thank Prof Guo Jinhu who helped with experiment design and provided for research support. The authors also thank Prof Xu Ying for her help in providing latest associated biological references.

\section{References}

Acosta-Martínez M 2011 PI3K: an attractive candidate for the central integration of metabolism and reproduction. Frontiers in Endocrinology 2 110. (https://doi.org/10.3389/fendo.2011.00110)

Alvarez JD, Chen D, Storer E \& Sehgal A 2003 Non-cyclic and developmental stage-specific expression of circadian clock proteins during murine spermatogenesis. Biology of Reproduction 69 81-91. (https://doi.org/10.1095/biolreprod.102.011833)

Alvarez JD, Hansen A, Ord T, Bebas P, Chappell PE, Giebultowicz JM, Williams C, Moss S \& Sehgal A 2008 The circadian clock protein BMAL1 is necessary for fertility and proper testosterone production in mice. Journal of Biological Rhythms 23 26-36. (https://doi. org/10.1177/0748730407311254)

Baburski AZ, Sokanovic SJ, Bjelic MM, Radovic SM, Andric SA \& Kostic TS 2016 Circadian rhythm of the Leydig cells endocrine function is attenuated during aging. Experimental Gerontology 73 5-13. (https:// doi.org/10.1016/j.exger.2015.11.002)

Bai D, Ueno L \& Vogt PK 2009 Akt-mediated regulation of NFkappaB and the essentialness of NFkappaB for the oncogenicity of PI3K and Akt. International Journal of Cancer 125 2863-2870. (https://doi. org/10.1002/ijc.24748)

Bellet MM, Zocchi L \& Sassone-Corsi P 2012 The RelB subunit of NFkappaB acts as a negative regulator of circadian gene expression. Cell Cycle $\mathbf{1 1}$ 3304-3311. (https://doi.org/10.4161/cc.21669)

Boden MJ, Varcoe TJ, Voultsios A \& Kennaway DJ 2010 Reproductive biology of female Bmal1 null mice. Reproduction 139 1077-1090. (https://doi.org/10.1530/REP-09-0523)

Bunger MK, Wilsbacher LD, Moran SM, Clendenin C, Radcliffe LA, Hogenesch JB, Simon MC, Takahashi JS \& Bradfield CA 2000 Mop3 is an essential component of the master circadian pacemaker in mammals. Cell 103 1009-1017. (https://doi.org/10.1016/s0092-8674(00)00205-1)

Chen MH, Li T, Ding CH, Xu YW, Guo LY \& Zhou CQ 2013a Growth differential factor-9 inhibits testosterone production in mouse theca interstitial cells. Fertility and Sterility 100 1444-1450. (https://doi. org/10.1016/j.fertnstert.2013.07.200)

Chen H, Zhao L, Kumazawa M, Yamauchi N, Shigeyoshi Y, Hashimoto S \& Hattori MA 2013b Downregulation of core clock gene Bmal1 attenuates expression of progesterone and prostaglandin biosynthesisrelated genes in rat luteinizing granulosa cells. American Journal of Physiology: Cell Physiology 304 C1131-C1140. (https://doi.org/10.1152/ ajpcell.00008.2013)

Chiou YY, Yang Y, Rashid N, Ye R, Selby CP \& Sancar A 2016 Mammalian period represses and de-represses transcription by displacing CLOCK-BMAL1 from promoters in a cryptochrome-dependent manner. PNAS 113 E6072-E6079. (https://doi.org/10.1073/pnas.1612917113)

Dierickx P, Van Laake LW \& Geijsen N 2018 Circadian clocks: from stem cells to tissue homeostasis and regeneration. EMBO Reports 19 18-28. (https://doi.org/10.15252/embr.201745130)

Fahrenkrug J, Georg B, Hannibal J, Hindersson P \& Gras S 2006 Diurnal rhythmicity of the clock genes Per1 and Per2 in the rat ovary. Endocrinology 147 3769-3776. (https://doi.org/10.1210/en.2006-0305)

Ghoneum A \& Said N 2019 PI3K-AKT-mTOR and NFkB pathways in ovarian cancer: implications for targeted therapeutics. Cancers 11. (https://doi.org/10.3390/cancers11070949)

Gilioli L, Marino M, Simoni M \& Casarini L 2017 The regulation of LHCGRdependent signaling is linked to circadian gene expression. Endocrine Abstracts 49 EP1131. (https://doi.org/10.1530/endoabs.49.EP1131)

Guo Z \& Yu Q 2019 Role of mTOR signaling in female reproduction. Frontiers in Endocrinology 10 692. (https://doi.org/10.3389/fendo.2019.00692)

Huang N, Chelliah Y, Shan Y, Taylor CA, Yoo SH, Partch C, Green CB, Zhang H \& Takahashi JS 2012 Crystal structure of the heterodimeric CLOCK:BMAL1 transcriptional activator complex. Science 337 189-194. (https://doi.org/10.1126/science.1222804)

Hussain AR, Ahmed SO, Ahmed M, Khan OS, Al Abdulmohsen S, Platanias LC, Al-Kuraya KS \& Uddin S 2012 Cross-talk between NFkB and the PI3-kinase/AKT pathway can be targeted in primary effusion lymphoma (PEL) cell lines for efficient apoptosis. PLOS ONE 7 e39945. (https://doi.org/10.1371/journal.pone.0039945)

Liang X, Cheng S, Jiang X, He X, Wang Y, Jiang Z, Hou W, Li S, Liu Y \& Wang Z 2013 The noncircadian function of the circadian Clock gene in the regulation of male fertility. Journal of Biological Rhythms 28 208-217. (https://doi.org/10.1177/0748730413486873)

Liu Y, Johnson BP, Shen AL, Wallisser JA, Krentz KJ, Moran SM, Sullivan R, Glover E, Parlow AF, Drinkwater NR et al. 2014 Loss of BMAL1 in ovarian steroidogenic cells results in implantation failure in female mice. PNAS 111 14295-14300. (https://doi.org/10.1073/pnas. 1209249111)

McDearmon EL, Patel KN, Ko CH, Walisser JA, Schook AC, Chong JL, Wilsbacher LD, Song EJ, Hong HK, Bradfield CA et al. 2006 Dissecting the functions of the mammalian clock protein BMAL1 by tissue-specific rescue in mice. Science 314 1304-1308. (https://doi.org/10.1126/ science.1132430)

Meng F, Liu L, Chin PC \& D'Mello SR 2002 Akt is a downstream target of NF-kappa B. Journal of Biological Chemistry 277 29674-29680. (https:// doi.org/10.1074/jbc.M112464200)

Mereness AL, Murphy ZC, Forrestel AC, Butler S, Ko C, Richards JS \& Sellix MT 2016 Conditional deletion of Bmal1 in ovarian theca cells disrupts ovulation in female mice. Endocrinology 157 913-927. (https:// doi.org/10.1210/en.2015-1645)

Musiek ES, Lim MM, Yang G, Bauer AQ, Qi L, Lee Y, Roh JH, OrtizGonzalez X, Dearborn JT, Culver JP et al. 2013 Circadian clock proteins regulate neuronal redox homeostasis and neurodegeneration. Journal of Clinical Investigation 123 5389-5400. (https://doi.org/10.1172/ JCI70317)

Pan X, Taylor MJ, Cohen E, Hanna N \& Mota S 2020 Circadian clock, timerestricted feeding and reproduction. International Journal of Molecular Sciences 21 E831. (https://doi.org/10.3390/ijms21030831)

Panda S, Antoch MP, Miller BH, Su AI, Schook AB, Straume M, Schultz PG, Kay SA, Takahashi JS \& Hogenesch JB 2002 Coordinated transcription of key pathways in the mouse by the circadian clock. Cell 109 307-320. (https://doi.org/10.1016/s0092-8674(02)00722-5)

Park HJ, Park SJ, Koo DB, Lee SR, Kong IK, Ryoo JW, Park YI, Chang KT \& Lee DS 2014 Progesterone production is affected by unfolded protein response (UPR) signaling during the luteal phase in mice. Life Sciences 113 60-67. (https://doi.org/10.1016/j.Ifs.2014.07.033)

Ratajczak CK, Boehle KL \& Muglia LJ 2009 Impaired steroidogenesis and implantation failure in Bmal1-/- mice. Endocrinology 150 1879-1885. (https://doi.org/10.1210/en.2008-1021)

Salminen A, Huuskonen J, Ojala J, Kauppinen A, Kaarniranta K \& Suuronen T 2008 Activation of innate immunity system during aging: NF-kB signaling is the molecular culprit of inflamm-aging. Ageing Research Reviews 7 83-105. (https://doi.org/10.1016/j.arr.2007.09.002)

Sellix MT 2015 Circadian clock function in the mammalian ovary. Journal of Biological Rhythms 30 7-19. (https://doi. org/10.1177/0748730414554222) 
Sen A \& Hoffmann HM 2020 Role of core circadian clock genes in hormone release and target tissue sensitivity in the reproductive axis. Molecular and Cellular Endocrinology 501 110655. (https://doi.org/10.1016/j. mce.2019.110655)

Shearman LP, Sriram S, Weaver DR, Maywood ES, Chaves I, Zheng B, Kume K, Lee CC, van der Horst GT, Hastings MH et al. 2000 Interacting molecular loops in the mammalian circadian clock. Science $\mathbf{2 8 8}$ 1013-1019. (https://doi.org/10.1126/science.288.5468.1013)

Shibui K, Uchiyama M, Okawa M, Kudo Y, Kim K, Liu X, Kamei Y, Hayakawa T, Akamatsu T, Ohta K et al. 2000 Diurnal fluctuation of sleep propensity and hormonal secretion across the menstrual cycle. Biological Psychiatry 48 1062-1068. (https://doi.org/10.1016/s00063223(00)00912-4)

Shimizu T, Hirai Y, Murayama C, Miyamoto A, Miyazaki H \& Miyazaki K 2011 Circadian Clock genes Per2 and clock regulate steroid production, cell proliferation, and luteinizing hormone receptor transcription in ovarian granulosa cells. Biochemical and Biophysical Research Communications 412 132-135. (https://doi.org/10.1016/j.bbrc.2011.07.058)

Spengler ML, Kuropatwinski KK, Comas M, Gasparian AV, Fedtsova N, Gleiberman AS, Gitlin II, Artemicheva NM, Deluca KA, Gudkov AV et al. 2012 Core circadian protein CLOCK is a positive regulator of NFkappaB-mediated transcription. PNAS 109 E2457-E2465. (https://doi. org/10.1073/pnas.1206274109)

Takahashi JS 2017 Transcriptional architecture of the mammalian circadian clock. Nature Reviews: Genetics 18 164-179. (https://doi.org/10.1038/ nrg.2016.150)

Tian Y, Shen W, Lai Z, Shi L, Yang S, Ding T, Wang S \& Luo A 2015 Isolation and identification of ovarian theca-interstitial cells and granulose cells of immature female mice. Cell Biology International 39 584-590. (https:// doi.org/10.1002/cbin.10426)

Wang Y, Gu F, Deng M, Guo L, Lu C, Zhou C, Chen S \& Xu Y 2016 Rotating shift work and menstrual characteristics in a cohort of Chinese nurses. BMC Women's Health 16 24. (https://doi.org/10.1186/s12905-016$0301-y)$

Wang W, Yin L, Bai L, Ma G, Zhao C, Xiang A, Pang W, Yang G \& Chu G 2017 Bmal1 interference impairs hormone synthesis and promotes apoptosis in porcine granulosa cells. Theriogenology 99 63-68. (https:// doi.org/10.1016/j.theriogenology.2017.05.010)

Wiggins G \& Legge M 2016 Cyclic variation of cellular clock proteins in the mouse estrous ovary. Journal of Reproduction and Infertility 17 192-198.
Wu R, Dang F, Li P, Wang P, Xu Q, Liu Z, Li Y, Wu Y, Chen Y \& Liu Y 2019 The circadian protein Period2 suppresses mTORC1 activity via recruiting Tsc1 to mTORC1 complex. Cell Metabolism 29 653-667.e6. (https://doi. org/10.1016/j.cmet.2018.11.006)

Xie M, Tang Q, Nie J, Zhang C, Zhou X, Yu S, Sun J, Cheng X, Dong N, Hu Y et al. 2020 BMAL1-downregulation aggravates Porphyromonas gingivalis-induced atherosclerosis by encouraging oxidative stress. Circulation Research 126 e15-e29. (https://doi.org/10.1161/ CIRCRESAHA.119.315502)

Xu J, Xu Y, Miao B, Deng M, Wang Y, Xiang P \& Zhou C 2015 Influence of menstrual cycle on the expression of clock genes in peripheral blood mononuclear cells in Macaca fascicularis. European Journal of Obstetrics, Gynecology, and Reproductive Biology 186 54-58. (https:// doi.org/10.1016/j.ejogrb.2015.01.003)

Xu J, Li Y, Wang Y, Xu Y \& Zhou C 2016 Loss of Bmal1 decreases oocyte fertilization, early embryo development and implantation potential in female mice. Zygote 24 760-767. (https://doi.org/10.1017/ S0967199416000083)

Yang G, Chen L, Grant GR, Paschos G, Song WL, Musiek ES, Lee V, McLoughlin SC, Grosser T, Cotsarelis G et al. 2016 Timing of expression of the core clock gene Bmal1 influences its effects on aging and survival. Science Translational Medicine 8 324ra16. (https://doi.org/10.1126/ scitranslmed.aad3305)

Young JM \& McNeilly AS 2010 Theca: the forgotten cell of the ovarian follicle. Reproduction 140 489-504. (https://doi.org/10.1530/REP-100094)

Zhang R, Lahens NF, Ballance HI, Hughes ME \& Hogenesch JB 2014 A circadian gene expression atlas in mammals: implications for biology and medicine. PNAS 111 16219-16224. (https://doi.org/10.1073/ pnas.1408886111)

Received 16 June 2020

First decision 13 July 2020

Revised Manuscript received 26 August 2020

Accepted 17 September 2020 